\title{
POTENSI AGROINDUSTRI KOPI LENGKUAS DI DESA MATANAIR KECAMATAN RUBARU KABUPATEN SUMENEP
}

\author{
*Sindi Arista Rahman, Ika Fatmawati Pramasari, Arfinsyah Hafid Anwari \\ Program Studi Agribisnis \\ Fakultas Pertanian Universitas Wiraraja Sumenep \\ Jl. Raya Sumenep Pamekasan KM 5 Patean Sumenep, Kode Pos : 69451 \\ sindiarista.94@gmail.com, ika_agribisnis@yahoo.co.id,arfinsyah@gmail.com
}

\begin{abstract}
ABSTRAK
Kopi Lengkuas merupakan campuran antara serbuk kopi dan bubuk lengkuas yang diproduksi untuk menghasilkan barang substitusi terhadap produk jamu yang biasanya memiliki cita rasa pahit.Tujuan penelitian ini adalah untuk menganalisis potensi usaha dan potensi pasar agroindustri kopi lengkuas di Desa Matanair Kecamatan Rubaru Kabupaten Sumenep. Penentuan lokasi dilakukan dengan sengaja (purposive) dan pengambilan sampel menggunakan teknik purposive sampling (sengaja) yaitu Kelompok Masyarakat APP Al-Ihsan sebagai produsen kopi lengkuas cap "Potre Alomampa". Metode analisis data yang digunakan yaitu analisis deskriptif dan analisis trend (permintaan dan penawaran).Hasil penelitian menunjukkan bahwa faktor-faktor pendukung seperti tata letak agroindustri, SDM, bahan baku, sarana prasarana dan teknologi masih belum terlaksana efektif dan efisien sepenuhnya. Potensi pasar produk kopi lengkuas berdasarkan aspek penawaran dan permintaan memiliki prospek yang baik untuk tahun 2016 - 2020 karena terjadi surplus (kelebihan) permintaan.Penawaran kopi lengkuas mengalami deficit (kekurangan) sehingga belum memenuhi permintaan pada tahun 2016-2020 sebesar 6.786.804,800 kg.
\end{abstract}

Kata Kunci: Agroindustri, Analisis Deskriptif, Analisis Trend, Kopi Lengkuas

\section{PENDAHULUAN}

Keberlangsungan kegiatan pada subsistem ini sangat bergantung pada sektor pertanian sebagai pemasok bahan baku.

Penurunan produksi pada sektor hulu pertanian (upstream agriculture)akan memberikan dampak negatifbagi kegiatan agroindustri sehingga akan mengurangi profit agroindustri sendiri. Selain mengolah makanan dan minuman, agroindustri juga mampu menghasilkan obat-obatan tradisional seperti jamu.
Alamat Koresponden:

Sindi Arista Rahman,

sindiarista.94@gmail.com,

Ika Fatmawati Pramasari, $\underline{\text { ika_agribisnis@yahoo.co.id }}$

\section{Arfinsyah Hafid Anwari}

arfinsyah@gmail.com

Jamu merupakan obat tradisional Indonesia yang dibuat dari tumbuhan, bahan hewan, bahan mineral, sediaan sarian (galenik) atau campuran dari bahan tersebut secara turun-temurun 
telah digunakan untuk pengobatan berdasarkan pengalaman (Harmanto dan M.Ahkam, 2007).Salah satu jamuyang terkenal adalah jamuMadura yangmempunyai kekhasan tersendiri antara lain rasanya pahit, segar, bau harum yang beraroma khas rempahrempah (Pramasari, 2013).

Lengkuas adalah salah satu tanaman obat yang sering digunakan sebagai bahan pembuatan jamu di Madura. Komoditas yang merupakan salah satu jenis dari tanaman biofarmaka ini dikelompokkan dalam anggota familia Zingiberaceae dengan ordo Zingeberales. Tanaman lengkuas memiliki nama ilmiah Lenguas galanga (Siswadi, 2006).

Rubaru merupakan salah satu Kecamatan penghasil komoditas lengkuas di Kabupaten Sumenep dan prospek pengembangan usaha taninya cukup baik untuk dilakukan karena kondisi tanah dan iklim yang cocok untuk penanaman komoditas tersebut (Dalilah, 2013).Menurut Dinas Pertanian dan Pangan Kabupaten Sumenep (2011-2015), Rubaru adalah Kecamatan yang paling banyak menghasilkan lengkuas selama tahun 2013-2015 dibandingkan Kecamatan lainnya di Kabupaten Sumenep yakni sebanyak 273,425, 266,403, 178,836 $\mathrm{kg}$.

Komoditas lengkuasselain diracik menjadi jamu juga mampu menghasilkan nilai tambah melalui subsistem agroindustri sehingga tercipta produk substitusi (pengganti) terhadap jamu yang biasanya memiliki cita rasa pahit yakni dengan mengolahnya dengan kopi. Kopi adalah salah satu minuman yang digemari oleh masyarakat Indonesia termasuk masyarakat Sumenep.Salah satu olahan kopi yang dikenal lama oleh masyarakat mengandung campuran tanaman obat adalah kopi jahe.Namun saat ini terdapat olahan kopi yang mengandung campuran tanaman obat lainnya seperti kopi lengkuas.

Kopi lengkuas merupakan campuran antara serbuk kopi dan bubuk lengkuasyang mempunyai aroma dan cita rasa yang berbeda serta memiliki khasiat yang baik untuk tubuh.Produk kopi lengkuas tersebut diolah pada agroindustri yang terletak di desa Matanair Kecamatan Rubaru Kabupaten Sumenep.

Keberlangsungan agroindustri kopi lengkuas tentunya dipengaruhi oleh faktor-faktor pendukung sepertiketersediaan bahan baku, SDM, teknologi, aspek pasar (permintaan dan penawaran) dan lain-lain Agroindustri yang sudah berdiri cukup lama tersebut sudah menerapkan salah satu jenis manajemen dalam pengelolaan usaha seperti manajemen pemasaran, namun penerapannya belum maksimal sehingga sampai saat ini sehingga belum diketahui potensi pasarnya 
dengan baik mengingat produk tersebut adalah produk baru.

Pengetahuan yang kurang baik mengenai potensi pasar (permintaan dan penawaran) di masa saat ini maupun yang akan datang akan membuat agroindustri kesulitan dalam mengimbangi jumlah kopi lengkuas yang harus ditawarkan dengan jumlah permintaan yang dibutuhkan masyarakat. Jika hal tersebut terus terjadi maka akan berdampak pada keberlangsungan agroindustri karena produk harus bersaing dengan produk olahan kopi lainnya yang sejenis.

Oleh karena itu perlu dilakukan suatu penelitian lebih rinci mengenai potensi agroindusti kopi lengkuas yang meliputi potensi usaha agroindustridan potensi pasar produk kopi lengkuas cap "Potre Alomampa".

\section{METODOLOGI PENELITIAN}

Pemilihan lokasi penelitian ditentukan secara purposive (sengaja) dengan pertimbangan bahwa daerah tersebut merupakan kecamatan penghasil komoditas lengkuas terbanyak di Kabupaten Sumenep dan satusatunya sentra agroindustri yang mengolah kopi dengan campuran bubuk lengkuas di Kabupaten Sumenep.

Penentuan sampel

penelitiandilakukan dengan menggunakan teknik purposive sampling (sengaja) yaitu Kelompok Masyarakat APP Al-Ihsan sebagai produsen kopi lengkuas cap "Potre Alomampa" produsen yang melakukan produksi secara kontinyu. Sumber data berasal dari data primer yaitu produsen dan tenaga kerja di agroindustri kopi lengkuas. Selain itu penelitian ini berasal dari data sekunder seperti Badan Pusat Statistik (BPS),dinas Pertanian dan Tanaman Pangan Kabupaten Sumenep, jurnal, buku, artikel dan skripsi sebagai refrensi penelitian terdahulu.

Metode analisis yang digunakan untuk menjawab tujuanpenelitian pertama yaitu analisis deskriptif untuk menjabarkan deskriptif dengan mengamati fenomena-fenomena yang terjadi sepertilayout pabrik, sarana dan prasarana yang digunakan, ketersediaan bahan baku, penggunaan teknologi, dan aspek Sumber Daya Manusia (SDM).

Untuk menjawab tujuan penelitian kedua digunakan alat analisis trend tentangpenawaran dan permintaan kopi lengkuas. Data time series yang digunakan dalam penelitian yaitu selama kurun waktu 2011-2015 dan metode peramalan dilakukan untuk mengetahui jumlah penawaran dan permintaan kopi lengkuas untuk tahun 2016-2020. Metode trend yang digunakan adalah metode kuadrat terkecil (least square method) dengan rumus sebagai berikut (Harmono, 2011) :

$$
\mathrm{Y}=\mathrm{a}+\mathrm{bX}
$$


Keterangan:

$\mathrm{Y}=$ Variabel yang akan dibuat garis trendnya (produksi dan konsumsi)

$\mathrm{X}=$ Indeks periode waktu.

a =Intersep (nilai variable padaperiode awal. Nilai $\mathrm{Y}$ apabila $\mathrm{X}=0$ ).

$\mathrm{b}=$ Slope (koefisien trend $=$ percobaan nilai variabel per periode).

Rumus untuk mencari nilai a dan $\mathrm{b}$ :

$\mathrm{a}=\Sigma \mathrm{Y}: \mathrm{n}$

$\mathrm{b}=\Sigma \mathrm{XY}: \Sigma \mathrm{X}^{2}$

\section{HASIL PENELITIAN}

ANALISIS POTENSI USAHA AGROINDUSTRI KOPI

\section{LENGKUAS}

Adapun faktor-faktor pendukung dalam kegiatan usaha kopi lengkuas yaitu:

\section{Tata Letak (Lay agroindustri}

Berdasarkan penggambaran lay out dijelaskan bahwa tata letak peralatan agroindustri saat ini belum dapat dikatakan berjalan efektif dan efisien. Hal ini karena tempat produksi atau dapur yang digunakan untuk proses pengolahan masih digabung dengan dapur rumah tangga sehingga peralatan untuk pembuatan kopi lengkuas diletakkan berdampingan dengan peralatan dapur lainnya. Kondisi ini membuat waktu produksi tidak berjalan efektif karena ruang produksi juga digunakan untuk kegiatan memasak dan membuat produk lain seperti dodol, snack bawang, abon lengkuas.

Peralatan untuk mesin penggiling lengkuas ditempatkan di rumah salah satu anggota Pokmas APP Al-Ihsan yang letaknya sekitar 75,3 meter dari dapur produksi sehingga mengakibatkan waktu lebih lama dalam melakukan proses produksi. Jarak antara dapur dengan tempat pengemasan hanya sekitar 2 meter. Pada ruang kemasan peralatan seperti hand sealer dan continous sealer sudah diletakkan dengan terartur dan rapi sehingga proses pengemasan berjalan efektif dan efisien.

\section{Sumber Daya Manusia (SDM)}

Manajemen Sumber Daya Manusia (SDM) pada usaha kopi lengkuas meliputi:

\section{A. Pembagian Job Description}

Ibu Sri Wahyuni sebagai direktur utama agroindustri menanggung hak dan kewajiban para pengurus inti dan tenaga kerja yang berjumlah total 5 orang yang masing-masing2 orang bertugas dan bertanggung jawab di bagian produksi, 2 orang di bagian pengemasan dan 1 orang di bagian pemasaran.

\section{B. Tingkat PendidikanTenaga Kerja}

Tingkat pendidikan untuk pengurus seperti ketua, bendahara, pengawas sekretaris, seksi umum, dan seksi operasional rata-rata lulusan 
SMA dan S1 sehingga hal ini dapat menjadi prospek yang cukup baik bagi agroindustri karena dapat terus menciptakan ide, strategi dan inovasi baru untuk pengembangan usaha. Sedangkan 5 orang yang rata-rata tingkat pendidikan mereka hanya lulusan SMP dan SMA.

\section{Prosedur Perekrutan Tenaga Kerja}

Proses pengrekrutan tenaga kerja di agroindustri kopi cap Potre Alomampa tidak melalui prosedur yang rumit. Semua tenaga kerja yang bekerja di Potre Alomampa Grup merupakan anggota Pokmas APP Al-Ihsan dan direkrut secara langsung oleh pemilik. Jadi tidak terdapat kriteria, seleksi (wawancara dan test ) serta masa percobaan. Jumlah anggota yang direkrut sebagai karyawan sebesar 5 orang dari 40 anggota yang ada.

D. Pengembangan Sumber Daya Manusia

Upaya peningkatan, pengembangan, dan pembentukan tenaga kerja perlu dilakukan suatu pembinaan, pendidikan dan pelatihan bagi semua pihak yang terlibat dalam usaha kopi lengkuas tersebut agar kemampuan kerja yang dimiliki bisa meningkat sehingga pada akhirnya mampu meningkatkan efektivitas dan produktifitas dalam usaha. Semua tenaga kerja di agroindustri tersebut pernah beberapa kali mendapatkan pelatihan seperti pelatihan tentang proses pengemasan yang baik dari Dinas Perindustrian dan Perdagangan (DISPERINDAG) yang dilaksanakan di Hotel Utami Sumekar dan Hotel C1. Selain itu, beberapa tenaga kerja juga pernah mendapatkan pelatihan di BLK (Balai Latihan Kerja) di Sumenep.

\section{Bahan Baku}

\section{A. Potensi Komoditas Lengkuas}

Rubaru merupakan Kecamatan yang dikenal sebagai sentra penghasil lengkuas terbanyak di Kabupaten Sumenep. Hal ini karena sebagian besar petani di desa tersebut menanam komoditas lengkuas karena tekstur dan struktur tanah di daerah tersebut cocok untuk tanaman tersebut. Jenis tanah grumusol yang terbentuk dari material halus berlempung, memiliki warna kelabu hitam, dan bersifat subur lebih mendominasi sehingga sangat mendukung bagi pengembangan usaha tani tanaman lengkuas.

Selain itu, sistem usaha tani untuk tanaman lengkuas di Kecamatan Rubaru Kabupaten Sumenep telah banyak dilakukan secara monokultur dan intensif di tanah tegalan. Berdasarkan uraian tersebut dapat dikatakan bahwa potensi produksi komoditas lengkuas di Kecamatan tersebut sangat baik.

\section{B. Ketesediaan Bahan Baku (Lengkuas dan Kopi) \\ Selama berproduksi kopi} lengkuas, agroindustri tidak memilik 
kendala dalam penyediaan bahan baku lengkuas. Hal ini karena ketersediaan tanaman lengkuas di lingkungan sekitar sangat melimpah. Beberapa tahun yang lalu agroindustri selalu menyuplai dari petani di sekitar agroindustri untuk memperoleh tanaman lengkuas, namun saat ini produsen memiliki demplot sendiri seluas $1 / 8$ ha yang ditanami lengkuas sehingga ketersediaan bahan baku selalu melimpah.

Potensi komoditas kopi di daerah sekitar maupun kabupaten Sumenep sangat kecil. Hal ini karena di daerah tersebut bukan merupakan sentra penghasil kopi. Adapun jumlah produksi kopi menurut Badan Pusat Statistik kabupaten Sumenep (2016), jumlah total produksi kopi yang dihasilkan di Kabupaten Sumenep hanya sebanyak 1,35 ton. Pada 27 Kecamatan di Kabupaten Sumenep, hanya ada 4 Kecamatan yang menghasilkan komoditas kopi dengan Kecamatan Rubaru sebagai pensuplai sebanyak 0,81 ton.

Kondisi ini mengakibatkan produsen menggunakan kopi oven asal Malang dengan varietas Arabika dan membeli dengan harga Rp.43.000,00/kg di Pasar Anom dalam penyediaan bahan baku kopi.

\section{Sarana dan Prasarana}

Aliran listrik maupun air di daerah tersebut mudah diperoleh, hal ini karena Desa Matanair bukan daerah pelosok dan hanya berada pada jarak $\pm 7 \mathrm{~km}$ dari pusat kota. Aliran listrik yang digunakan oleh agroindustri dalam melakukan produksi yaitu sebesar 900 watt yang digabung dengan kebutuhan listrik rumah tangga. Agroindustri tidak mengalami kekurangan maupun kendala dalam penyediaan air bersih. Hal ini karena agroindustri menggunakan air sumur untuk memenuhi kebutuhan air produksi maupun untuk rumah tangga sehingga tidak ada permasalahan dalam pemenuhan air bersih.

Saat ini belum terdapat sarana transportasi atau angkutan umum seperti angkot dan ojek di lingkungan sekitar. Hal ini karena mobilitas masyarakat yang tidak terlalu padat dan pada umumnya masyarakat sudah memiliki kendaraan pribadi seperti sepeda motor.

Pada aspek sarana prasarana, kondisi jalan di daerah agroindutri juga tidak rusak karena sudah beraspal dan hanya beberapa tempat terdapat sedikit kerusakan namun hal ini tidak berpengaruh besar terhadap akses jalan menuju ke lokasi produksi. Letak lokasi produksi yang juga ada di pinggir jalan mengakibatkan proses distribusi berjalan dengan lancar.

\section{Teknologi}

Peralatan yang digunakan untuk pembuatan kopi lengkuas tersebut tidak seluruhnya menggunakan alat/mesin yang modern.Terdapat beberapa tahap produksi yang masih menggunakan 
cara manual dan alat yang sederhana seperti wajan, saringan dan lain-lain. Sedangkan untuk tahap produksi yang lainnya, produsen sudah menggunakan mesin yang modernseperti mesin penggiling otomatis, mesin hand sealer dan mesin continous sealer.

ANALISIS POTENSI PASAR KOPI LENGKUAS

\section{Trend Penawaran Kopi Lengkuas}

Perkembangan jumlah penawaran kopi lengkuas selama 2011-2015 mengalami peningkatan setiap tahun walaupun pada tahun 2014 mengalami stagnasi (tetap). Rata-rata pertumbuhan jumlah produksi mencapai 0,163\% per tahun. Data produksi kopi lengkuas cap Potre Alomampa dapat dilihat pada tabel 1 .

Tabel 1. Perkembangan Penawaran Kopi Lengkuas Cap Potre AlomamI

\begin{tabular}{ccc}
\multicolumn{2}{c}{ Tahun 2011-2015 } \\
\hline Tahun & Penawraran/Produksi (kg) & Pertumbuhan (\%) \\
\hline 2011 & 1.920 & - \\
2012 & 2.304 & 0,200 \\
2013 & 2.688 & 0,167 \\
2014 & 2.688 & 0,000 \\
2015 & 3.456 & 0,286 \\
\hline Jumlah & 13,056 & 0,653 \\
\hline Rata-rata & 2611,200 & 0,163 \\
\hline
\end{tabular}

Hasil penawaran kopi lengkuas tahun 2011-2015 secara grafik dapat dilihat pada gambar 1 .

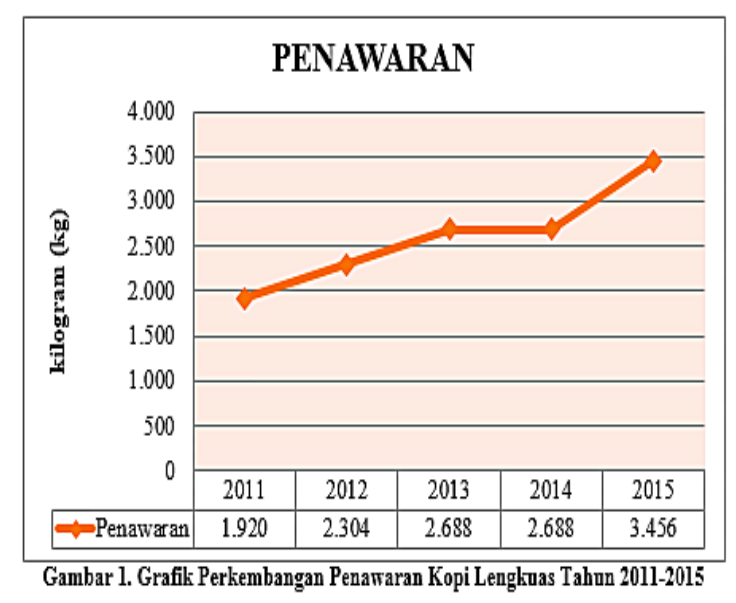

Berdasarkan hasil analisis trend dengan menggunakan metode kuadrat terkecil diperoleh persamaan regresi yaitu: $Y=2.611,200+345,600 \mathrm{X}$. Berdasarkan perhitungan trend dengan menggunakan bantuan aplikasiSPSS 16 diperoleh $\mathrm{R}$ square $\left(\mathrm{R}^{2}\right)=0,920$ atau 92\%. Hal ini berarti variabel dependent (penawaran) dipengaruhi oleh variabel independent (indeks tahun) sebesar $92 \%$ sedangkan sisanya sebesar $8 \%$ dipengaruhi oleh variabel atau faktor lain di luar model.

Sedangkan nilai signifikasi pada tabel anova menujukkan hasil sebesar 0,010 lebih kecil dari taraf kesalahan $0,05(5 \%)$ yang artinya bahwa analisis trend mampu memberikan nilai akurasi yang nyata dalam meramalkan jumlah produksi kopi lengkus pada tahun 2016-2020. Hasil peramalan penawaran produk kopi lengkuas untuk tahun 2016 hingga 2020 dapat dilihat pada tabel 2.

Tabel 2. Hasil Proyeksi Penawaran Kopi Lengkuas Cap Potre Alomampa

\begin{tabular}{ccc} 
Tahun 2016-2020 & & \\
\hline Tahun & Produksi (kg) & Pertumbuhan (\%) \\
\hline 2016 & $3.648,000$ & - \\
2017 & $3.993,600$ & 0,095 \\
2018 & $4.339,200$ & 0,087 \\
2019 & $4.684,800$ & 0,080 \\
2020 & $5.030,400$ & 0,074 \\
\hline Jumlah & $\mathbf{2 1 . 6 9 6 , 0 0 0}$ & $\mathbf{0 , 3 3 6}$ \\
\hline Rata-rata & $\mathbf{4 . 3 3 9 , 2 0 0}$ & $\mathbf{0 , 0 8 4}$ \\
\hline
\end{tabular}


Berdasarkan tabel 2 terlihat bahwa produksi untuk kopi lengkuas cap Potre Alomampa akan mengalami peningkatan produksi untuk tahun 2016-2020dengan rata-rata pertumbuhan sebesar $0,084 \%$.

Pada tahun 2016-2020 jumlah total penawaran/produksi kopi lengkuas cap Potre Alomampa $(21.696,000 \mathrm{~kg})$ lebih besar dibandingkan dengan jumlah total penawaran/produksi kopi lengkuas cap Potre Alomampa pada 5 tahun sebelumnya yaitu dengan selisih $8.256,000 \mathrm{~kg}$. Grafik hasil peramalan penawaran kopi lengkuas untuk tahun 2016-2020 dapat dilihat pada gambar 2.

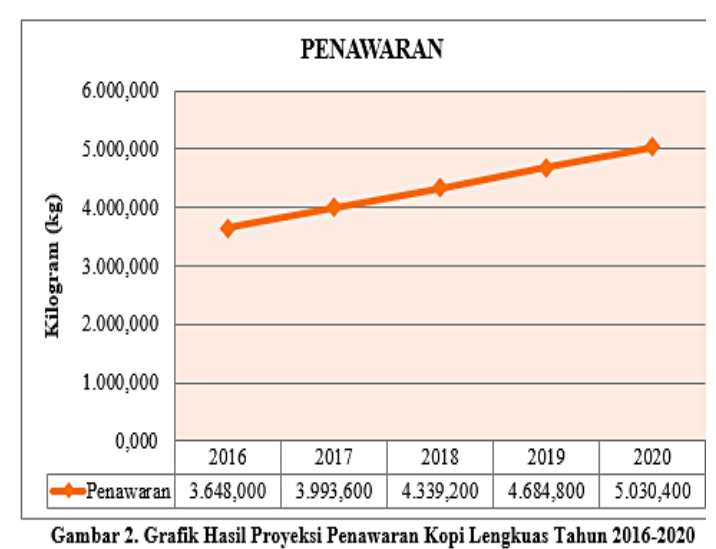

\section{Trend Permintaan Kopi \\ Lengkuas \\ Analisis permintaan kopi} lengkuas diperoleh berdasarkan jumlah konsumsi kopi per tahunnya. Perhitungan permintaan kopi secara asumsi diperoleh dengan cara menghitung hasil perkalian antara jumlah penduduk di Kabupaten Sumenep dengan jumlah konsumsi kopi per kapita berdasarkan hasil survei AEKI (Asosiasi Eksportir dan Industri
Kopi Indonesia) selama 5 tahun (20112015). Berikut hasil asumsi perkembangan permintaan kopi di Kabupaten Sumenep tahun 2011-2015 dapat dilihat pada tabel 3

Tabel 3. Asumsi Perkembangan Permintaan Kopi Di Kabapaten Sumenep Tahun 2011-2015

\begin{tabular}{ccc}
\hline Tahun & Permintaan/Konsumsi $(\mathrm{kg})$ & Pertumbuban (\%) \\
\hline 2011 & $911.913,990$ & - \\
2012 & $990.421,600$ & 0,086 \\
2013 & $1.061 .211,000$ & 0,071 \\
2014 & $1.099 .218,060$ & 0,036 \\
2015 & $1.168 .603,170$ & 0,063 \\
\hline Jumlah & $\mathbf{5 . 2 3 1 . 3 6 7 , 8 2 0}$ & 0,256 \\
\hline Rata-rata & $\mathbf{1 . 0 4 6 . 2 7 3 , 5 6 4}$ & 0,064 \\
\hline
\end{tabular}

Sumber: Data Sekunder Diooleh, 2017

Berdasarkan tabel 3 permintaan kopi terus mengalami peningkatan dari tahun 2011 sampai tahun 2015 dengan rata-rata pertumbuhan sebesar $0,064 \%$. Hal tersebut dikarenakan konsumsi per kapita mengalami peningkatan yang diantaranya dipengaruhi oleh faktor jumlah penduduk Kabupaten Sumenep yang juga bertambah setiap tahun. Jumlah penduduk di Kabupaten Sumenep dan konsumsi kopi pada AEKI dapat dilihat pada tabel 4 berikut ini.

Tabel 4. Jumlah Penduduk Kabupaten Sumenep dan Konsumsi Survei Asosiasi \begin{tabular}{ccc}
\multicolumn{3}{c}{ Eksportir Dan Industri Kopi Indonesia (AEKI) Tahun 2011-2015 } \\
\hline Tahun & $\begin{array}{c}\text { Jumlah Penduduk Sumenep } \\
\text { (Jiwa) }\end{array}$ & $\begin{array}{c}\text { Konsumsi survei AEKI } \\
\text { (kg/kapita/tahun) }\end{array}$ \\
\hline 2011 & 1.048 .177 & 0,87 \\
2012 & 1.053 .640 & 0,94 \\
2013 & 1.061 .211 & 1,00 \\
2014 & 1.067 .202 & 1,03 \\
2015 & 1.072 .113 & 1,09 \\
\hline Jumlah & $\mathbf{5 3 0 2 . 3 4 3}$ & 4,93 \\
\hline
\end{tabular} Keterangan : *Asosiasi Eksportir Dan Industri Kopi Indonesia

Hasil permintaan kopi lengkuas tahun 2011-2015 secara grafik dapat dilihat pada gambar 3. 


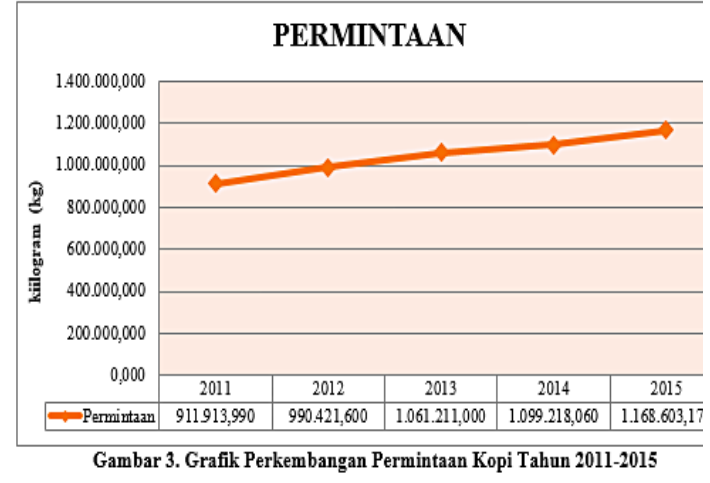

Berdasarkan hasil analisis trend dengan menggunakan metode kuadrat terkecil diperoleh persamaan garis trend permintaan kopi lengkuas yang persamaan regresinya yaitu:

$$
\mathrm{Y}=1.046 .273,560+62.217,480 \mathrm{X} \text {. }
$$

Perhitungan trend dengan menggunakan bantuan aplikasi SPSS 16diperoleh $\mathrm{R}$ square $\left(\mathrm{R}^{2}\right)=0,988$ atau $98,8 \%$. Hal ini berarti variabel dependent (permintaan) dipengaruhi oleh variabel independent (indeks tahun) sebesar $98,8 \%$ sedangkan sisanya sebesar $01,2 \%$ dipengaruhi oleh variabel atau faktor lain di luar model.

Sedangkan nilai signifikasi pada tabel anova menujukkan hasil sebesar 0,001. Nilai signifikasi lebih kecil dari taraf kesalahan 0,05 (5\%) yang artinya bahwa analisis trend mampu memberikan nilai akurasi yang nyata dalam meramalkan jumlah permintaan kopi pada tahun 2016-2020.

Hasil peramalan permintaan produk kopi lengkuas untuk tahun 2016 hingga 2020 dapat dilihat pada tabel 5.

\section{Tabel 5. Hasil Proyeksi Permintaan Kopi Tahun 2016-2020}

\begin{tabular}{ccc}
\hline Tahun & Permintaan $(\mathrm{kg})$ & Pertumbuhan $(\%)$ \\
\hline 2016 & $1.232 .926,000$ & - \\
2017 & $1.295 .143,480$ & 0,050 \\
2018 & $1.357 .360,960$ & 0,048 \\
2019 & $1.419 .578,440$ & 0,046 \\
2020 & $1.481 .795,920$ & 0,044 \\
\hline Jumlah & $\mathbf{6 . 7 8 6 . 8 0 4 , 8 0 0}$ & $\mathbf{0 , 1 8 8}$ \\
\hline Rata-rata & $\mathbf{1 . 3 5 7 . 3 6 0 , 9 6 0}$ & $\mathbf{0 , 0 4 7}$ \\
\hline Sur
\end{tabular}

Berdasarkan tabel 5 terlihat bahwa permintaan untuk kopi akan mengalami peningkatan terus-menerus untuk tahun 2016 sampai tahun 2020 dengan jumlah permintaan sebesar 6.786.804,800 kg. Sehingga diramalkan bahwa untuk tahun 20162020 jumlah permintaan akan semakin naik. Hal ini mengakibatkan produk kopi lengkuas akan memiliki peluang pasar yang tinggi karena permintaan terhadap kopi di Kabupaten Sumenep tahun 2016-2020 juga tinggi dengan rata-rata pertumbuhan sebesar 0,047\% per tahun. Perhitungan proyeksi permintaan kopi lengkuas di Kabupaten Sumenep tahun 2016-2020 beserta grafik dapat dilihat pada gambar 4 .

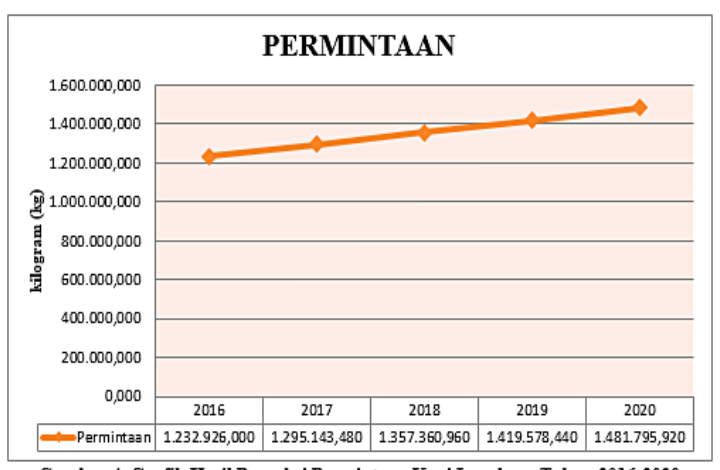

Gambar 4. Grafik Hasil Proyeksi Permintaan Kopi Lengkuas Tahun 2016-2020

\section{Selisih Antara Penawaran dan}

\section{Permintaan}

Selisih antara trend penawaran dan trend permintaan Kopi Lengkuas cap Potre Alomampa untuk tahun 2016-2020 dapat dilihat pada tabel 6 . 
Tabel 6. Selisih Antara Permintaan dan Penawaran 2011-2020

\begin{tabular}{cccr}
\hline Tahun & Permintaan (kg) & Penawaran $(\mathbf{k g})$ & \multicolumn{1}{c}{ Selisih (kg) } \\
\hline 2011 & $911.913,990$ & $1.920,000$ & $909.993,990$ \\
2012 & $990.421,600$ & $2.304,000$ & $988.117,600$ \\
2013 & $1.061 .211,000$ & $2.688,000$ & $1.058 .523,000$ \\
2014 & $1.099 .218,060$ & $2.688,000$ & $1.096 .530,060$ \\
2015 & $1.168 .603,170$ & $3.456,000$ & $1.165 .147,170$ \\
2016 & $1.232 .926,000$ & $3.648,000$ & $1.229 .278,000$ \\
2017 & $1.295 .143,480$ & $3.993,600$ & $1.291 .149,880$ \\
2018 & $1.357 .360,960$ & $4.339,200$ & $1.353 .021,760$ \\
2019 & $1.419 .578,440$ & $4.684,800$ & $1.414 .893,640$ \\
2020 & $1.481 .795,920$ & $5.030,400$ & $1.476 .765,520$ \\
\hline Jumlah & $\mathbf{l 2 . 0 1 8 . 1 7 2 , 6 2}$ & $\mathbf{3 4 . 7 5 2 , 0 0}$ & $\mathbf{1 1 . 9 8 3 . 4 2 0 , 6 2 0}$ \\
\hline Sumber: Data Primer dan Sekunder Diolah, 2017 &
\end{tabular}

Pada tabel 6 dilihat bahwa selama tahun 2011-2020 terjadi defisit (kekurangan) pada aspek produksi dan terjadi surplus (kelebihan) pada aspek permintaan yang disebabkan oleh meningkatnya jumlah penduduk.Surplus permintaan tertinggi terjadi pada tahun 2020 sebesar $(1.481 .795,920 \mathrm{~kg}-5.030,400 \mathrm{~kg})=$ $1.476 .765,520 \quad \mathrm{~kg}$ dan surplus permintaan terendah sebesar 909.993,990 kg yang terjadi pada tahun 2011.

\section{KESIMPULAN DAN SARAN}

\section{Kesimpulan}

1. Berbagai faktor pendukung yaitu lay-out/tata letak agroindustri, Sumber Daya Manusia (SDM), bahan baku, sarana dan prasarana serta teknologi belum dapat sepenuhnya dikatakan baik. Letak agroindustri saat ini masih belum berjalan efektif dan efisien karena letaknya yang terpencar. Sedangkan untuk aspek teknologi, agroindustri tidak sepenuhnya menggunakan alat/mesin yang modern dan beberapa tahap produksi masih menggunakan alat sederhana. Pada aspek bahan baku, Sumber Daya Manusia (SDM) dan sarana prasarana sudah dapat mendukung usaha agroindustri dan memiliki potensi yang baik untuk dikembangkan.

2. Potensi pasar produk kopi lengkuas dilihat dari aspek penawaran dan permintaan memiliki prospek pasaryang baik untuk tahun 2016 2020 karena terjadi surplus (kelebihan) permintaan dibandingkan dengan penawaran. Produksi atau penawaran kopi lengkuas mengalami defisit (kekurangan) sehingga belum memenuhi permintaan pada tahun 2016-2020 sebesar $6.786 .804,800 \mathrm{~kg}$. Oleh sebab itu perlu adanya peningkatan produksi untuk memenuhi jumlah permintaan yang ada.

\section{Saran}

1. Produsen kopi lengkuas perlu melakukan sebuah startegi pengembangan usaha untuk meningkatkan volume penjualan dan memperluas pangsa pasar yang disertai dengan peningkatan promosi.

2. Produsen perlu memperbaiki tata letak/lay-out agroindustri untuk mencapai efesiensi dalam kegiatan produksi.

3. Untuk mendapatkan mutu produk yang baik, produsen perlu memperhatikan kualitas (mutu) pada 
setiap tahap proses produksi mulai

dari penyediaan bahan, proses

pengolahan, dan pengemasan.

4. Sebaiknya produsen menambah tenaga kerja di pemasaran agar

proses penjualan produk kopi

lengkuas bisa berjalan efisien. 


\section{DAFTAR PUSTAKA}

AEKI.2013. Konsumsi Kopi Indonesia. Diambil dari: http://www.aekiaice.org/page/konsumsi-kopidomestik/id. (17April 2016)

Badan Pusat Statistik Sumenep. 20122016. Sumenep Dalam Angka.Sumenep : BPS.

Dalilah, 2013. Prospek Pengembangan Agribisnis Lengkuas (Alpinia Galanga L.Swartz).Skripsi. Fakultas Pertanian. Universitas Wiraraja Sumenep.

Damaijati, E. 2009.Metodologi Penelitian Agribisnis. Surabaya: Penerbit UPN Press.

Direktorat Jenderal Hortikultura. 2015. Statistik Produksi Hortikultura Tahun 2014. Kementerian Pertanian. Diambil dari http://hortikultura.pertanian.go.id Iwpcontent/uploads/2016/02/Statistik -Produksi-2014.pdf

November 2016).

Harmono. 2011. Manajemen Keuangan Berbasis Balanced Scorecard Pendekatan Teori, Kasus, dan Riset Bisnis. Jakarta: Bumi Aksara

Pramasari, I.F., A.H. Anwari, M. Harun, dan Alwiyah. 2013. Kelayakan Agrowisata Jamu Ramuan Madura Di Kabupaten Sumenep. JurnalCemara, Vol. 10, No. 1: Hal 6-9. (07 Oktober 2016)

Purba, S.N., Rahmanta, S.N. Lubis. 2014. Analisis Trend Permintaan, Penawaran, Dan Harga Gula Kristal Putih Di Provinsi Sumatera Utara.Journal On Social Economic Of Agriculture And Agribusiness Vol. 3, No. 3 Diambil dari http://jurnal.usu.ac.id/index.php/ce ress/article/view/8125/3506(07 Oktober 2016)
Rahardjo, P. 2012. Kopi Panduan Budidaya dan Pengolahan Kopi Arabika dan Robusta. Jakarta: Penebar Swadaya

Siswadi. 2006. Budidaya Tanaman Obat. Yogyakarta: PT Citra Aji Parama.

Soetriono, A.S. dan Rijanto. 2003. Pengantar Ilmu Pertanian.Jember: Banyumedia Publishing

Sugiyono. 2014. Memahami Penelitian Kualitatif. Bandung: Alfabeta

Tamimah, I. 2016. Potensi Agribisnis Usaha Tani Kelapa Di Kabupaten Sumenep. Skripsi. Fakultas Pertanian. Universitas Wiraraja Sumenep.

Wahyuni, S., K. Tarigan, dan S.T. Lubis. 2015. Analisis Trend Konsumsi Dan Produksi Susu Sapi Di Sumatera Utara vol4, no 5. Journal On Social Economic Of Agriculture And Agribusiness. Diambil dari http://jurnal.usu.ac.id/index.php/c eress/article/view/10686 (07 Oktober 2016)

Widowati, E.H. 2013. Potensi Agroindustri Kopi Di Kawasan Agro Tecno Park (Atp) Kabupaten Temanggung. Jurnal Litbang Provinsi Jawa Tengah, Vol. 11, No. 1: Hal 103-112. Diambil dari http://balitbang.jatengprov.go.id/ ejournal/index.php/jurnallitbangj ateng/article/view/84 (07 Oktober 2016) 